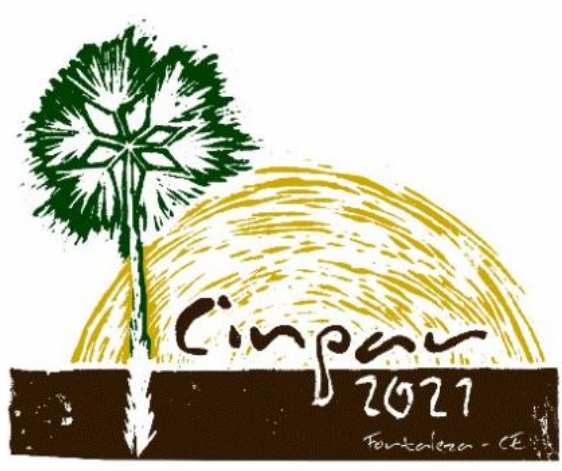

XVII Congresso Internacional sobre Patologia e

Reabilitação das Construções

XVII Congreso Internacional sobre Patología y Rehabilitación de las Construcciones

XVII International Conference on Pathology and Constructions Rehabilitation

FORTALEZA (Brasil), 3 a 5 de junho de 2021

https://doi.org/10.4322/CINPAR.2021.044

\title{
Manifestações patológicas decorrentes de infiltração em pavimentos de garagem - Estudo de caso em Salvador - BA
}

\author{
Pathological manifestations due to infiltration \\ in garage floors - Case study in Salvador - BA
}

\author{
Francisco Gabriel Santos SILVA ${ }^{1}$, Vinícius Almeida COELHO ${ }^{2}$, Luanne Bastos de Britto BARBOSA ${ }^{3}$ \\ ${ }^{1}$ Universidade Federal da Bahia, Escola Politécnica - Departamento de Construção e Estruturas, Brasil, \\ fgabriel.ufba@gmail.com \\ ${ }^{2}$ Universidade Federal da Bahia, Escola Politécnica - Programa de Pós-graduação em Engenharia Civil, Brasil, \\ mrvoelho@gmail.com \\ ${ }^{3}$ Universidade Federal da Bahia, Escola Politécnica - Programa de Pós-graduação em Engenharia Civil, Brasil, \\ lubastosb@gmail.com
}

\begin{abstract}
Resumo: É de fundamental importância que os sistemas construtivos apresentem desempenho satisfatório durante toda a vida útil das edificações para garantia de sua funcionalidade, segurança e habitabilidade. Dentre os sistemas que mais apresentam problemas construtivos está o sistema de impermeabilização, fundamental para proteção da edificação contra o ingresso de agentes agressivos e a ação de processos deletérios que envolvam a presença de umidade em elementos ou ambientes que deveriam permanecer estanques. Entretanto, seja por carência de especificação em projeto, falhas de manutenção ou execução inadequada, ainda são encontradas diversas manifestações decorrentes da infiltração de água devido à presença indesejada de umidade. $O$ presente estudo de caso avaliou manifestações patológicas decorrentes de infiltração nas garagens de um edifício da cidade de Salvador - BA. Foram utilizadas como técnicas de diagnóstico a pHmetria com solução de fenolftaleína, termografia infravermelha com câmera térmica e registro fotográfico in loco. Dentre os principais danos encontrados estavam a corrosão de elementos estruturais, degradação das juntas de dilatação, fissuração, falhas de rejunte e perda de aderência da camada impermeabilizante (manta asfáltica). Além da identificação, foi feito o diagnóstico das possíveis causas dos problemas listados, sendo detectada a existência de nível de lençol freático muito raso na região, avaliação do grau de risco estrutural, devido à corrosão em elementos resistentes, e sugestão de metodologias de reparo.
\end{abstract}

Palavras-chave: Infiltração; Diagnóstico; Patologia; Edifício; Garagem.

Abstract: It is of fundamental importance that the constructive systems present satisfactory performance during the entire useful life of the buildings to guarantee their functionality, safety, and habitability. Among those that present the most constructive problems is the waterproofing system, which is fundamental for protecting the building against the entry of aggressive agents and the action of harmful processes involving the presence of moisture in elements or environments that should remain watertight. However, due to lack of specification in the project, maintenance failures or inadequate execution, there are still several manifestations resulting from the infiltration of water due to the unwanted presence of moisture. The present case study evaluated pathological manifestations resulting from infiltration in the garages of a building in the city of Salvador - BA. As diagnostic techniques, pHmetry with phenolphthalein solution, infrared thermography with thermal camera and photographic recording on-site were used. Among the main damages found were corrosion of structural elements, degradation of expansion joints, cracking, failure of 
grout and loss of adhesion of the waterproofing layer (asphalt membrane). In addition to the identification, the possible causes of the listed problems were diagnosed along with the existence of a very shallow groundwater level in the region, assessment of the degree of structural risk due to corrosion in resistant elements, and suggestion of repair methodologies.

Keywords: Infiltration; Diagnostic; Pathology; Building; Garage.

\section{Introdução}

Tem-se observado a incidência cada vez maior de manifestações patológicas nas edificações com origens diversas. Tais fenômenos podem ser oriundas de falhas de projeto, más práticas de execução ou mesmo o emprego de materiais inadequados para as condições de exposição do ambiente onde a edificação está inserida e estão diretamente associados ao desgaste das estruturas, promovendo a redução progressiva do desempenho dos sistemas construtivos até níveis críticos onde a usabilidade e segurança das edificações são comprometidas. Neste cenário, os danos podem ser mais elevados do que aqueles previstos nos planos de manutenção e passam a exigir recursos significativos para realização de intervenções e reabilitação (ANTUNES, 2010; DAL MOLIN et al., 2016).

Os danos causados pelas infiltrações estão usualmente associados a falhas nos sistemas de impermeabilização, seja pelo emprego de técnicas inadequadas, pela falta de manutenção ou por avarias provocados no sistema impermeabilizante por agentes externos. Sob a perspectiva dos impactos econômicos, os recursos gastos para recuperação de problemas decorrentes de infiltração, na fase de utilização das edificações, são muito maiores do que os custos necessários para a realização de uma impermeabilização adequada na fase de obra (OLIVEIRA, 2015; MAGALHÃES et al., 2019).

A infiltração é uma das principais patologias encontradas nas edificações, caracterizada pelo ingresso e percolação indesejada de água nos sistemas construtivos. Dentre os danos associados à ocorrência de umidade nas estificações estão aqueles associados a critérios de habitabilidade, como manchamentos, goteiras, formação de eflorescências, descolamentos de revestimentos e desenvolvimento de microrganismos como fungos e bolores. Também há danos relacionados à estabilidade estrutural, como as fissurações, desplacamentos e corrosão das armaduras no concreto armado (MAGALHÃES et al., 2019).

A ocorrência de infiltrações afeta sensivelmente a estética das edificações, prejudicando de imediato a sua valorização. Além disso, a depender da magnitude dos danos, pode promover uma série de transtornos entre os usuários, reduzir a salubridade do ambiente e comprometer a durabilidade e resistência mecânica dos elementos construtivos (BARREIRA; ALMEIDA; DELGADO, 2016).

Sob tais condições, a infiltração reduz o desempenho e capacidade resistente dos elementos construtivos ao promover ou acelerar processos degradativos, afetando diretamente a durabilidade e a vida útil das edificações, fenômenos associados pela NBR 15575 (ABNT, 2013) à capacidade de resistir à ação dos agentes degradantes e o período em que os sistemas construtivos apresentam desempenho adequado frente às solicitações para as quais foram projetados, respectivamente.

Uma das consequências da presença de água nos materiais é a alteração de suas propriedades térmicas. Um dos principais efeitos é a mudança na capacidade térmica das regiões umedecidas, de modo que, sob uma mesma condição de exposição à radiação térmica, surgem diferenciais de temperatura entre as regiões secas e úmidas de um mesmo elemento. Conforme Rocha et al. (2018), tais diferenciais térmicos podem ser detectados por câmeras termográficas, apesar de serem pequenos. Sendo assim uma valiosa fonte de informação para deteç̧ão de infiltração e realização de reparos.

As análises termográficas podem ser realizadas de forma quantitativa ou qualitativa, sendo esta a mais simples e usual. A análise qualitativa procura identificar variações de temperatura nos elementos estudados em busca de anomalias em seu perfil térmico, atuando assim como uma espécie de mapa que destaca as regiões onde há água absorvida ou na superfície (ANDRADE E RESENDE, 2019). 
A termogravimetria também se destaca por permitir que sejam identificados pontos de infiltrações em elementos que não apresentam sinais visuais como manchamentos em sua superfície, cenário usualmente observado quando a anomalia está em fases iniciais (SANTOS; ROCHA; PÓVOAS, 2019), e em situações de difícil acesso, visto que os termogramas podem ser gerados a uma certa distância do objeto de estudo sem prejuízos para análises qualitativas (BARREIRA; ALMEIDA; DELGADO, 2016).

O presente trabalho teve como objetivo identificar manifestações patológicas decorrentes de infiltração nos pavimentos de garagem de uma edificação comercial, avaliar as ocorrências encontradas frente a possíveis causas e propor possíveis soluções.

\section{Metodologia}

O objeto deste estudo foram os 5 pavimentos de garagem de uma edificação comercial com 25 pavimentos, construída há 5 anos (Figura 1), situada em região com classe de agressividade ambiental tipo III, considerada forte pela NBR 6118 (ABNT, 2014), na cidade de Salvador - BA.

Foi inicialmente realizada entrevista com o responsável pela edificação, obtendo-se informações sobre os problemas mais evidentes, suas datas de origem e possíveis intervenções já realizadas. Em seguida, para identificação e avaliação das manifestações patológicas durante a vistoria, procedeu-se com inspeção visual in loco, captura de imagens com câmera profissional de alto zoom (Sony DSC H400), termografia infravermelha (FLIR C2 Profissional) e teste de pHmetria com solução alcóolica de fenolftaleína nas regiões com sinais de infiltração.

Também foram avaliadas as condições nos entornos da edificação, devido à presença de umidade na garagem do subsolo e, após detecção das anomalias, foi feito o diagnóstico do problema e identificadas as prováveis causas das manifestações encontradas, sendo apresentadas alternativas para solucionamento dos problemas.

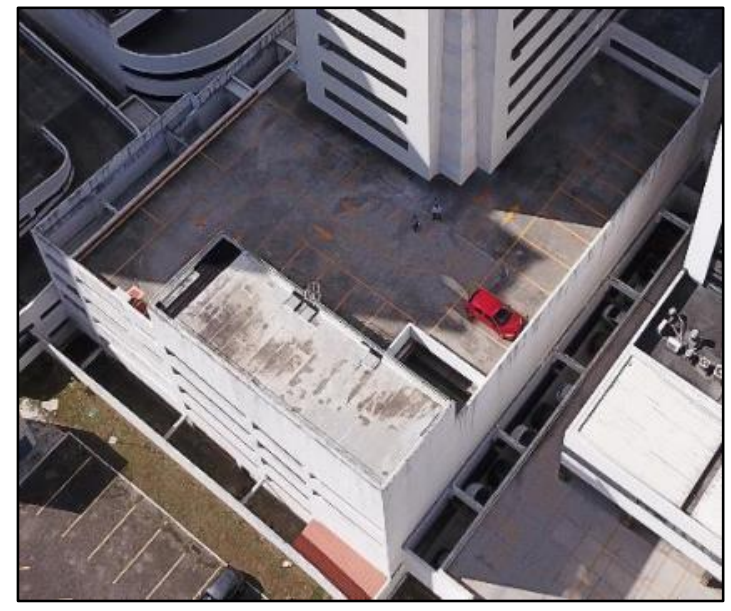

Figura 1 - Vista geral das garagens. 


\section{Resultados e discussão}

\subsection{Cobertura}

Durante a vistoria na cobertura da edificação foram identificadas fissuras no rodapé das muretas (Figura 2), facilmente identificadas como oriundas do descolamento da camada impermeabilizante (manta asfáltica), como pode ser observado na Figura 3.
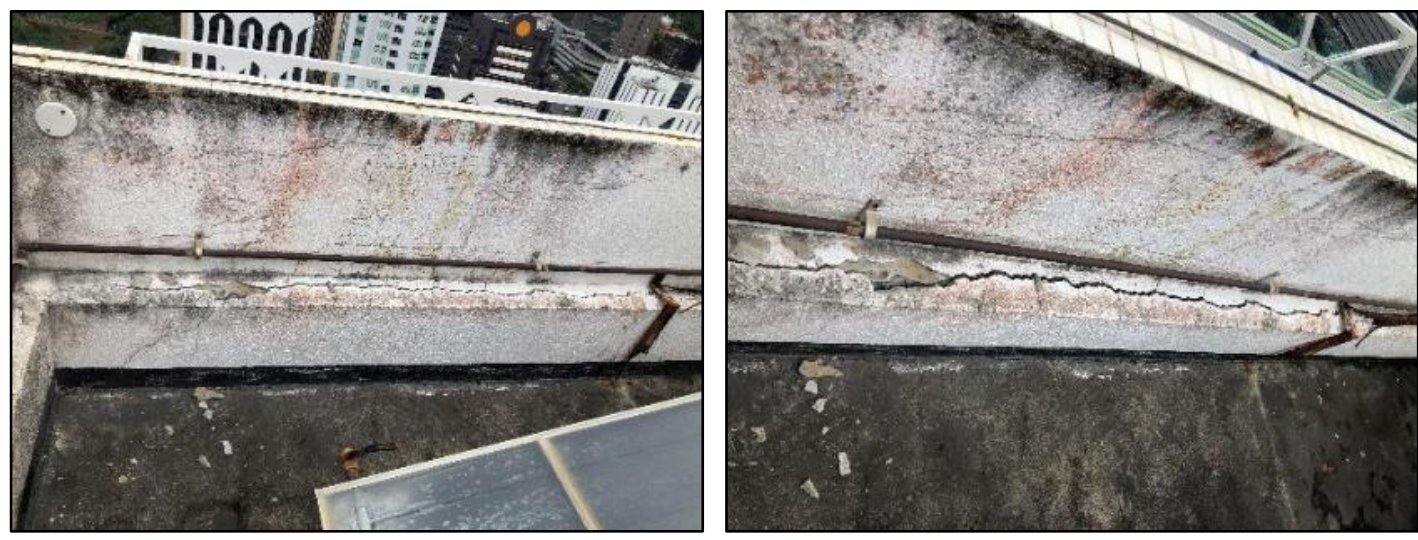

Figura 2 - Cobertura - Fissuração no rodapé da mureta
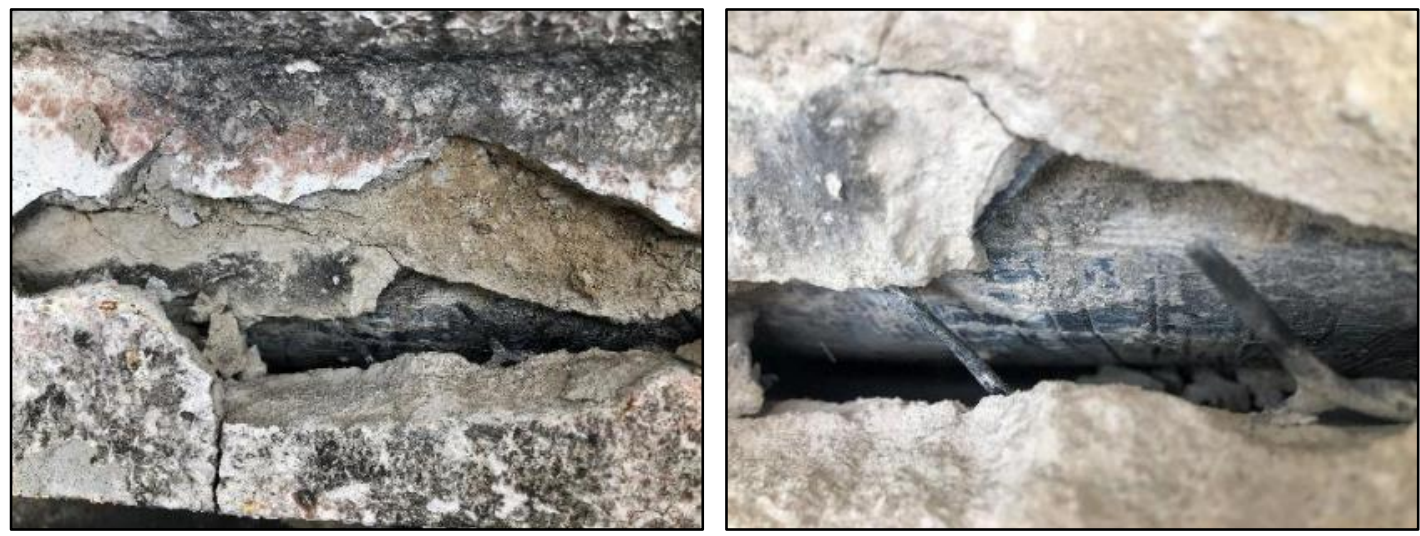

Figura 3 - Cobertura - Perda de aderência da camada impermeabilizante

\subsection{Garagem G3}

A vistoria começou no pavimento de garagem superior, G3, onde foram observadas fissuras generalizadas no rodapé das muretas e no piso (Figura 4), com sinais de intervenções prévias (Figura 5) e crescimento de vegetação (Figura 6) em alguns pontos.
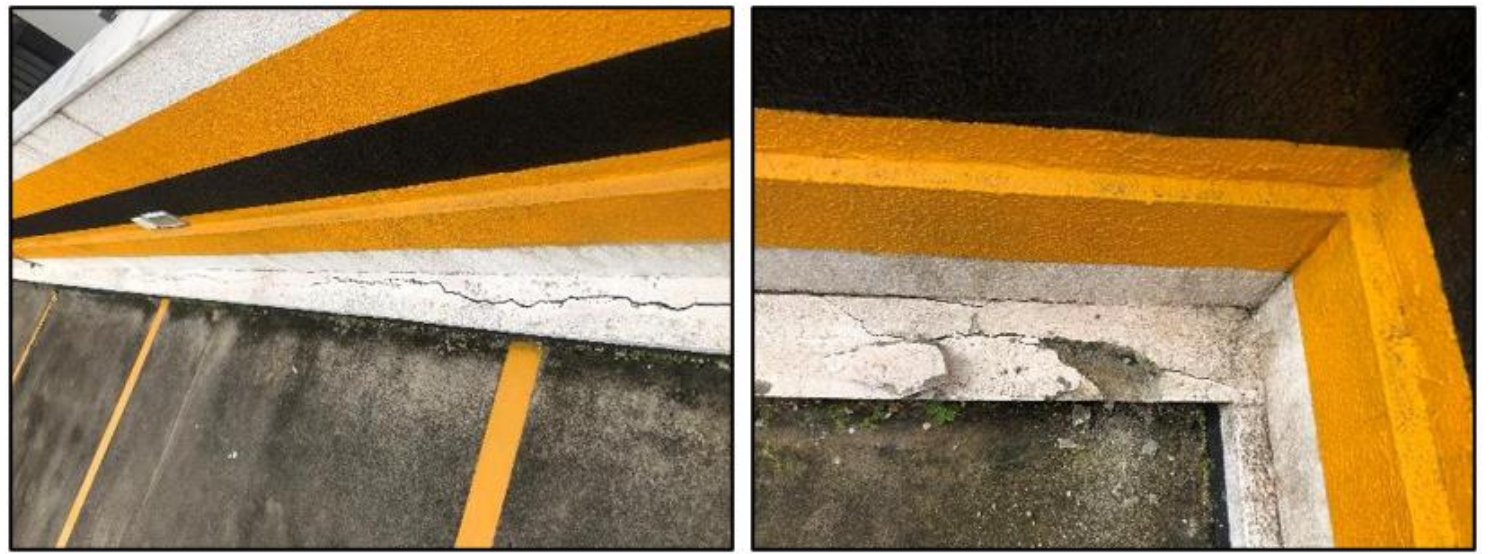

Figura 4 - G3 - Fissuração no rodapé da mureta (esq.); Destacamento do concreto (dir.)

Manifestações patológicas decorrentes de infiltração em pavimentos de garagem 

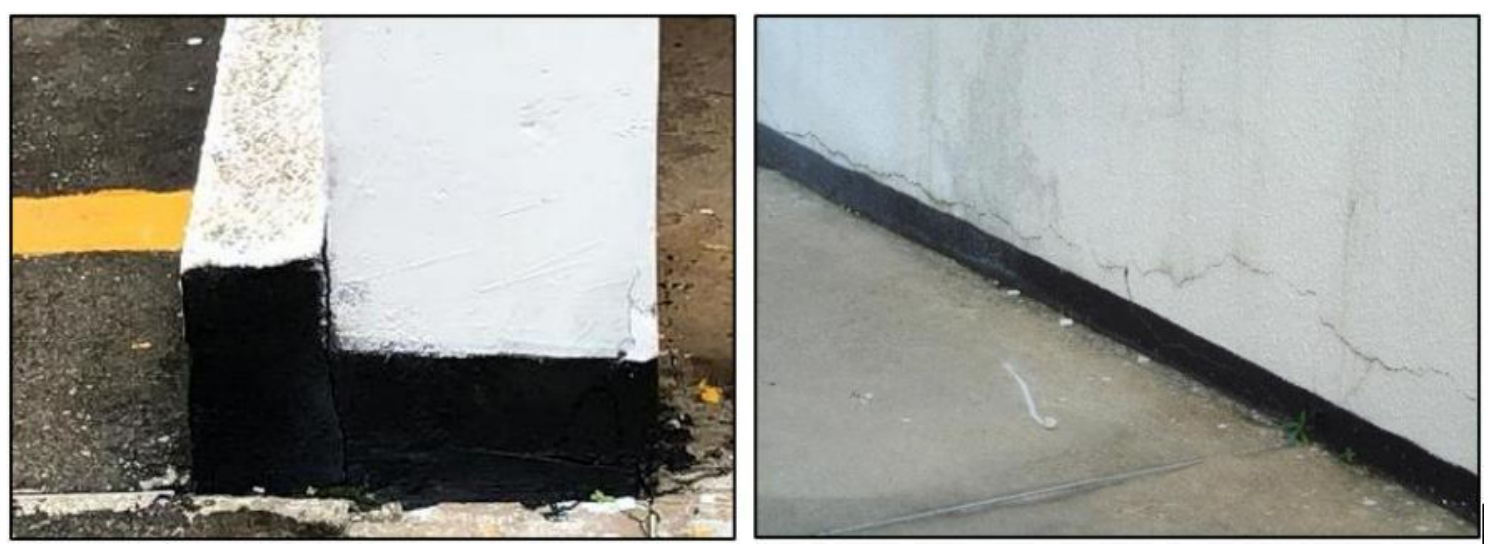

Figura 5 - G3 - Fissuração no rodapé com sinais de intervenção (esq.); Fissuração na parte inferior da mureta(dir.)
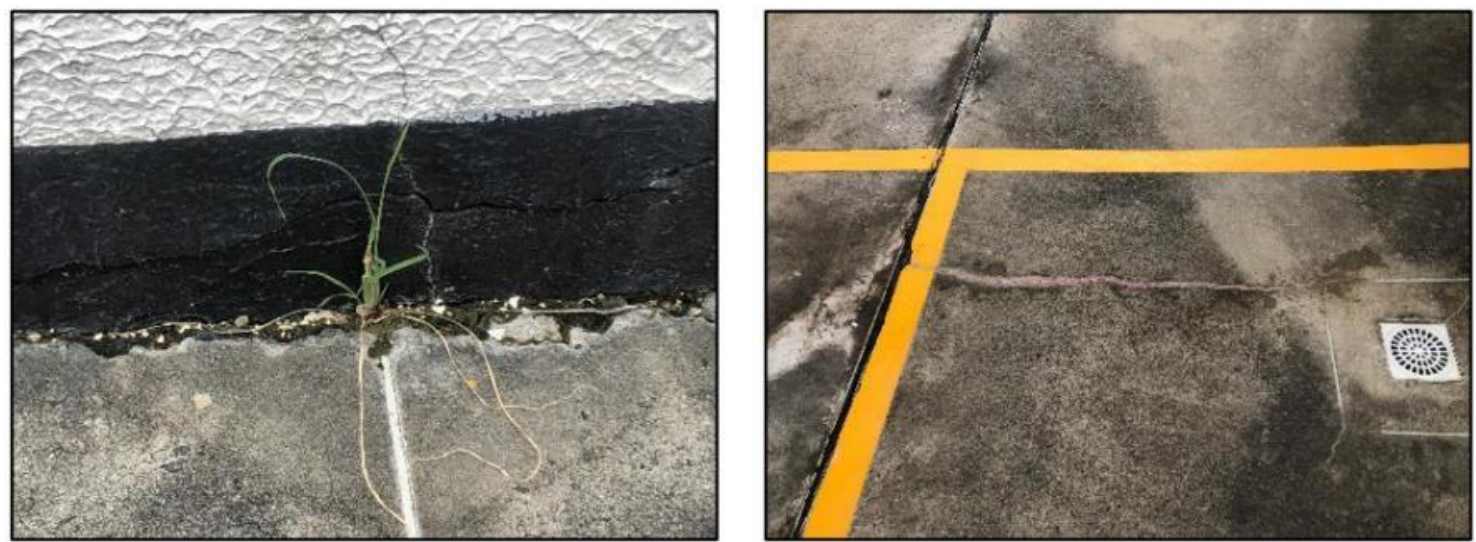

Figura 6-G3 - Crescimento de vegetação (esq.); Fissuração no piso (dir.)

Por meio da pHmetria foi confirmada a infiltração de água através das fissuras no piso, evidenciadas pela mudança de cor da solução de fenolftaleína ao entrar em contato com o hidróxido de cálcio lixiviado do concreto, como pode ser observado na Figura 7 - esq. Também foram encontradas regiões com desplacamento devido à corrosão com o concreto em torno da armadura já carbonatado (Figura 7 - dir.) e danos na junta de movimentação do piso e regiões próximas, com acúmulo de água e sinais de infiltração (Figura 8).
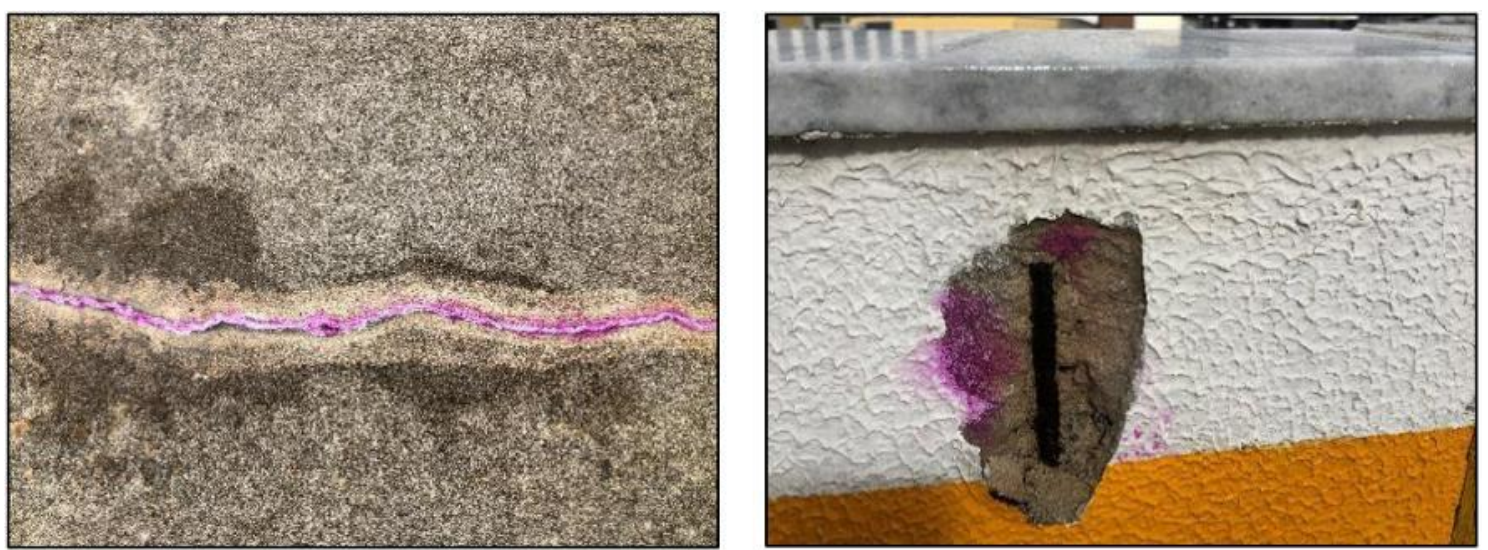

Figura 7 - G3 - pHmetria no piso (esq.); pHmetria em desplacamento com corrosão (dir.) 

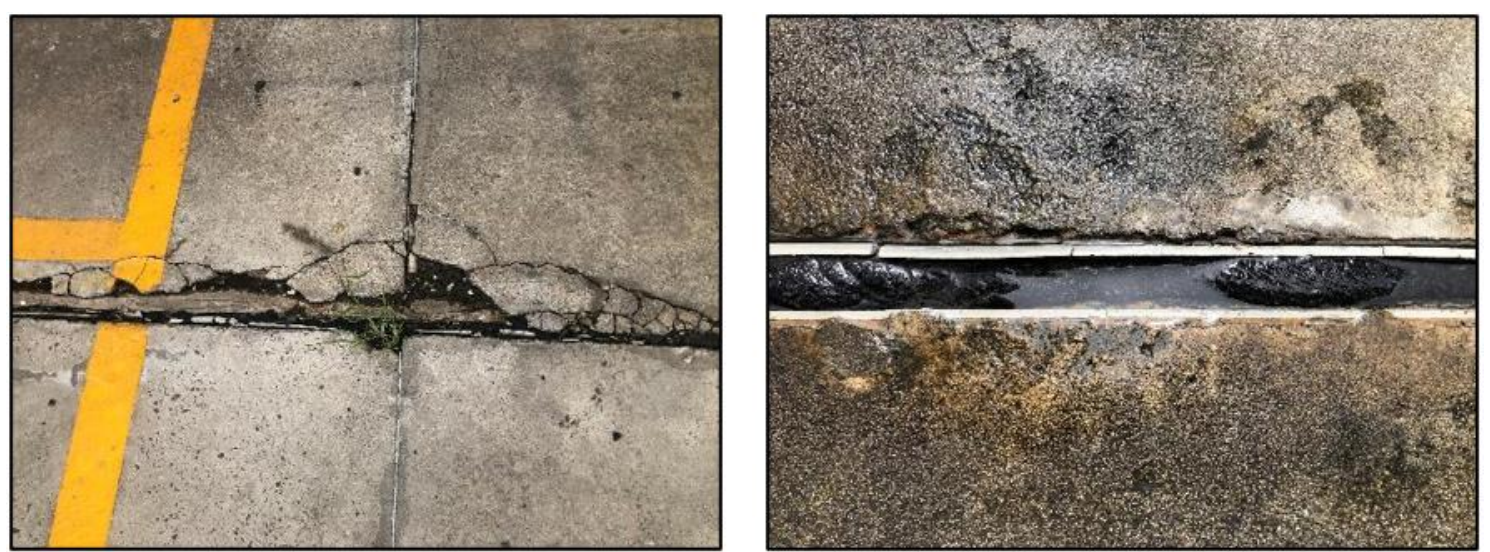

Figura 8-G3 - Danos na junta de movimentação (esq.); Acúmulo de água na junta do piso (dir.)

\subsection{Garagem G2}

Na sarjeta da entrada da garagem G2 (Figura 9a) foi identificado o crescimento de vegetação e fechamento incorreto do ralo de drenagem, o que possibilita que resíduos indesejados adentrem e ocasionem problemas na tubulação (Figura 9b). Por meio do teste de pHmetria foi também identificado sinal de infiltração nesta região.
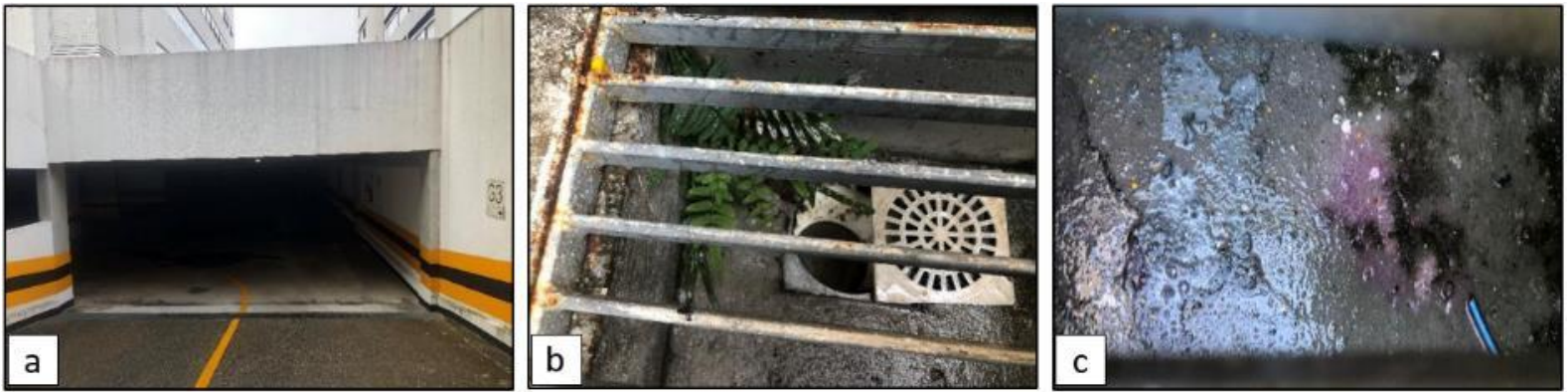

Figura 9-G2 - Entrada (a); Vegetação e danos no ralo (b); Sinais de infiltração por pHmetria (c)

Na parte interna da garagem foram identificadas infiltrações no teto abaixo da junta de movimentação do pavimento G3, além disso, também ocorreu acúmulo de água na região próxima à junta do piso (Figura 10) e pontos onde foi identificada corrosão (Figura 11 - dir.).

Registrou-se longa fissuração na interface entre a viga abaixo da junta de movimentação do pavimento G3 e a laje, oriunda do preenchimento desta interface com material rígido, incompatível com as movimentações estruturais (Figura 11 - esq.).
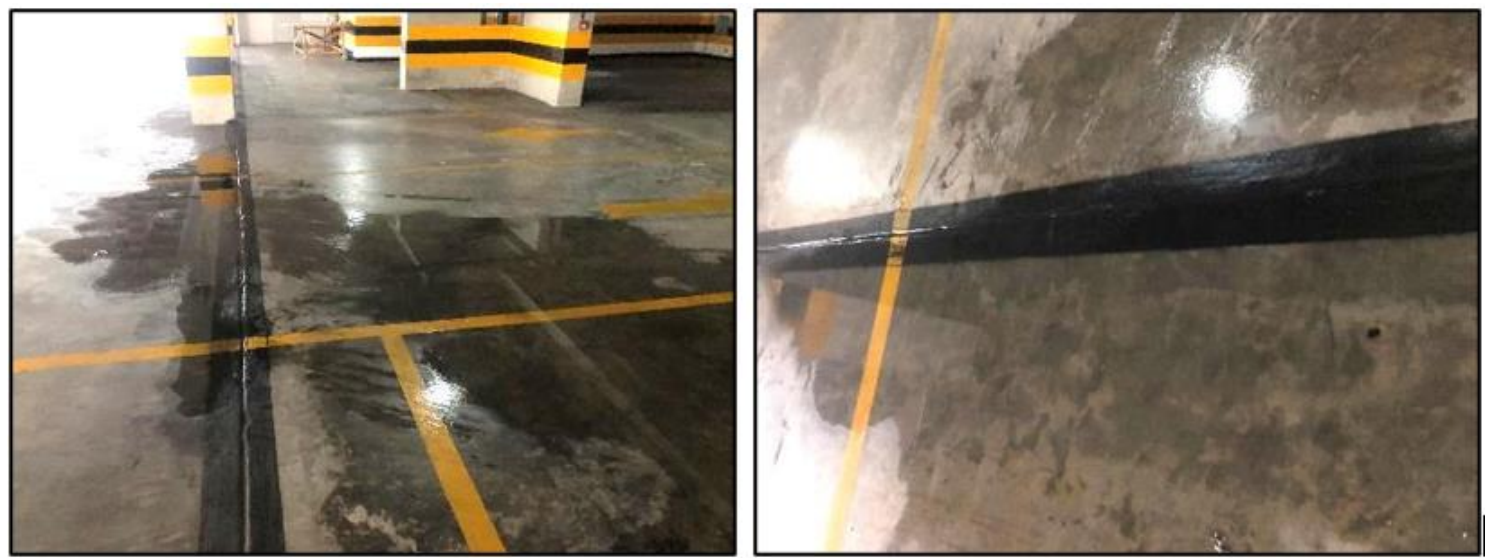

Figura 10 - G2 - Acúmulo de água na região da junta de movimentação 

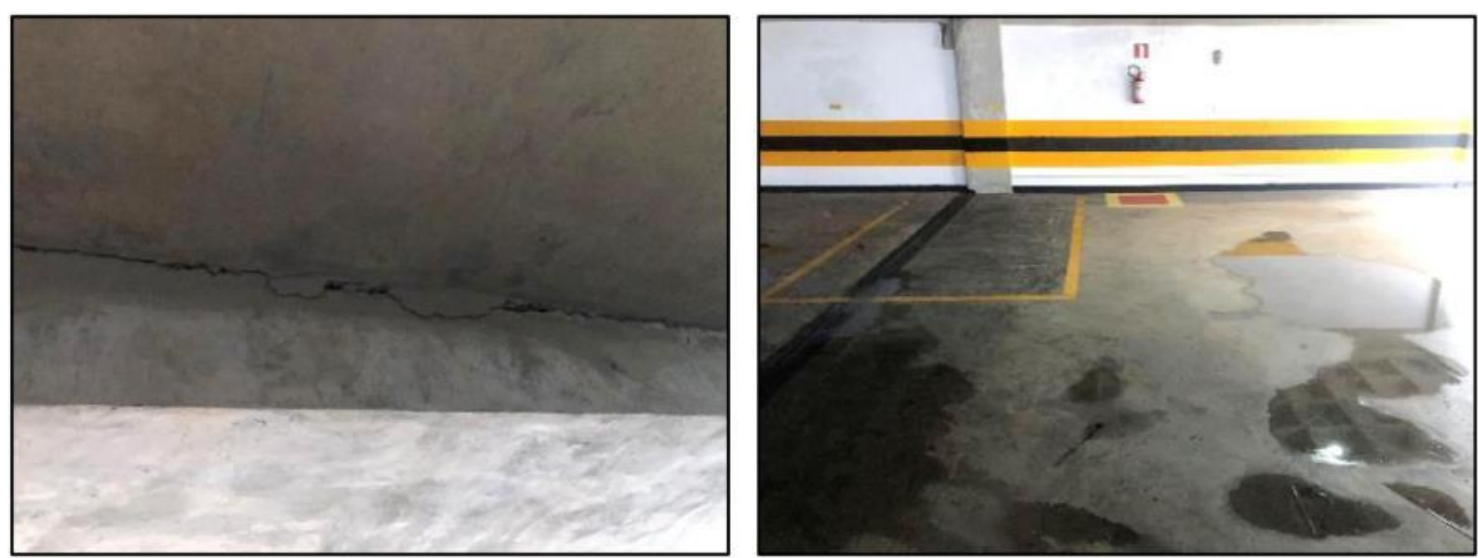

Figura 11 - G2 - Fissura na viga próxima à junta de movimentação (esq.); acúmulo de água e corrosão no piso (dir.)

Por meio da termografia infravermelha foi possível detectar pontos de acúmulo de umidade nas paredes externas, região da rampa de acesso G2-G3. Pode-se observar as áreas afetadas nos termogramas da Figura 12 e Figura 13, caracterizadas por regiões com temperatura significativamente inferior (manchas roxas) em relação ao resto da parede.
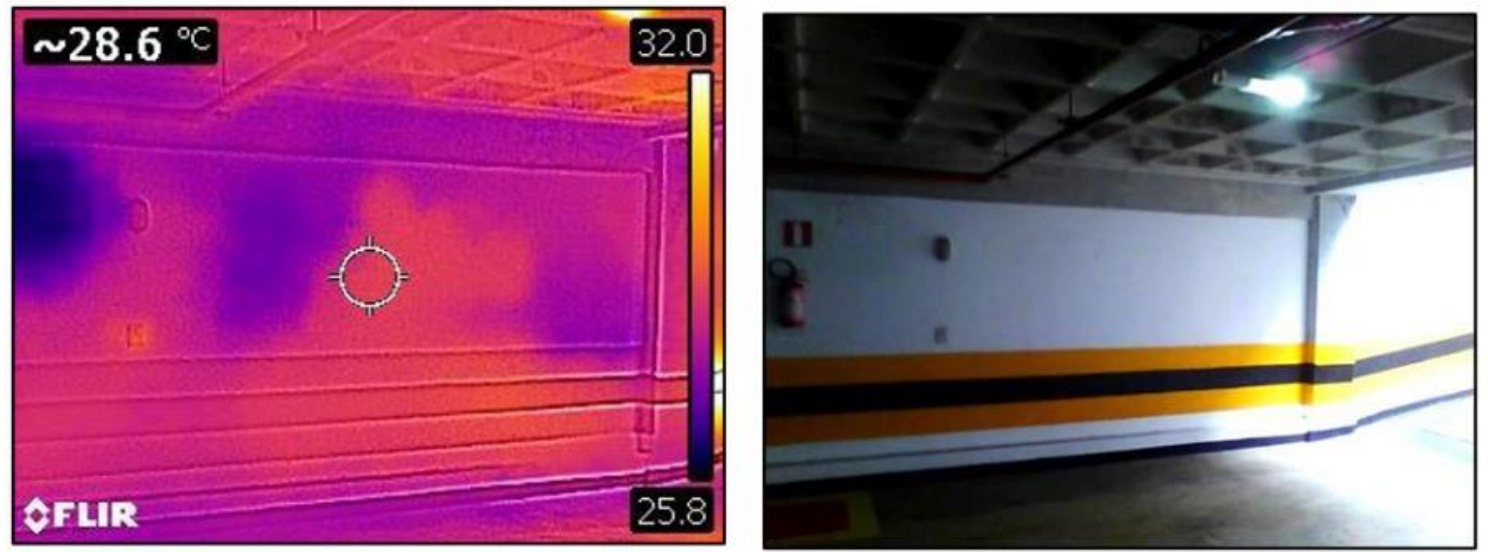

Figura 12 - G2 - Termograma da parede de entrada
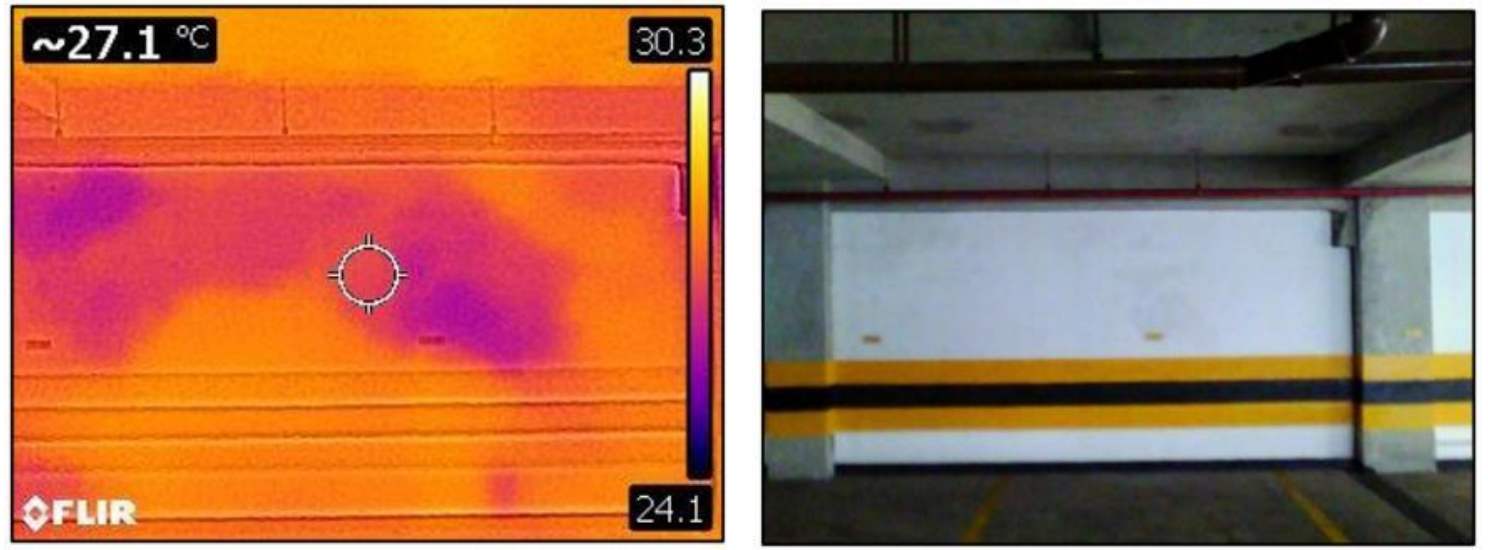

Figura 13 - G2 - Termograma da parede (continuação da Figura 12)

Inspecionando-se o lado externo das paredes destacadas pela termografia, foram identificadas fissuras e danos próximos às juntas de movimentação do revestimento que atuam como pontos de entrada para umidade oriunda das águas pluviais (Figura 14). 

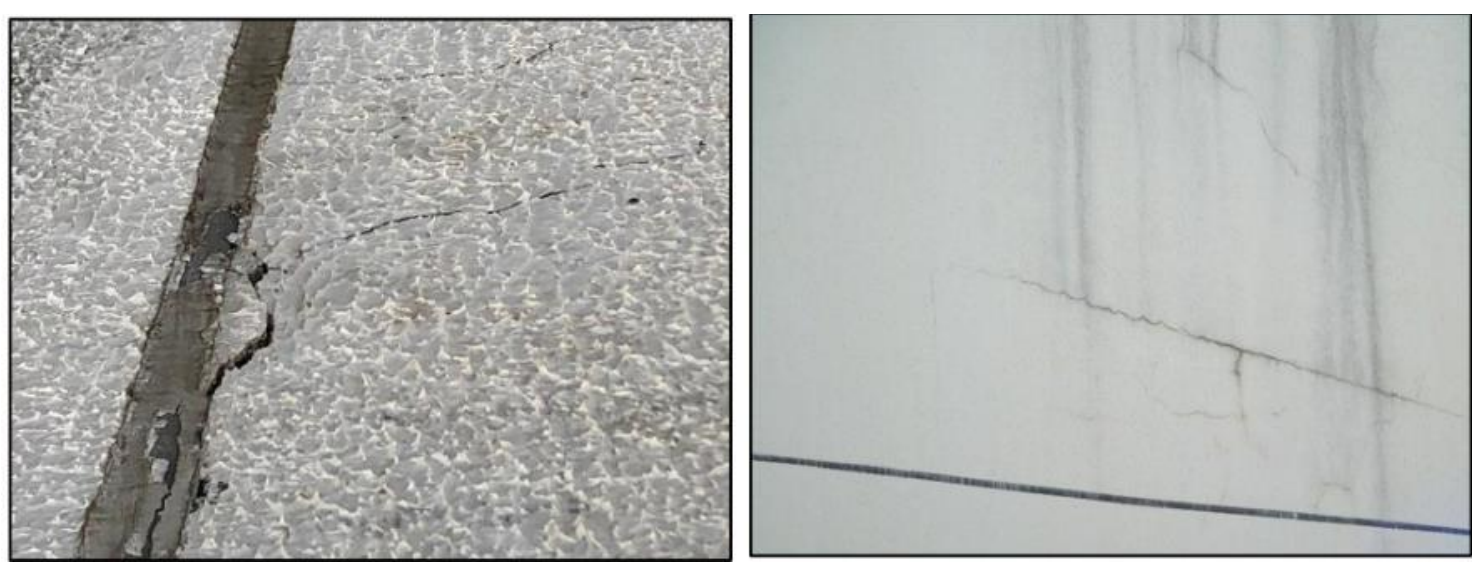

Figura 14 - G2 - Lado externo das paredes da entrada (região da Figura 12)

\subsection{Garagem G1}

No pavimento G1 foram identificadas fissuras e lixiviação de hidróxido de cálcio na calha da sarjeta de entrada do pavimento $\mathrm{G} 2$ que apresentou sinais de infiltração (Figura 15). A passagem da água é tamanha que a região abaixo apresentou acúmulo de água.
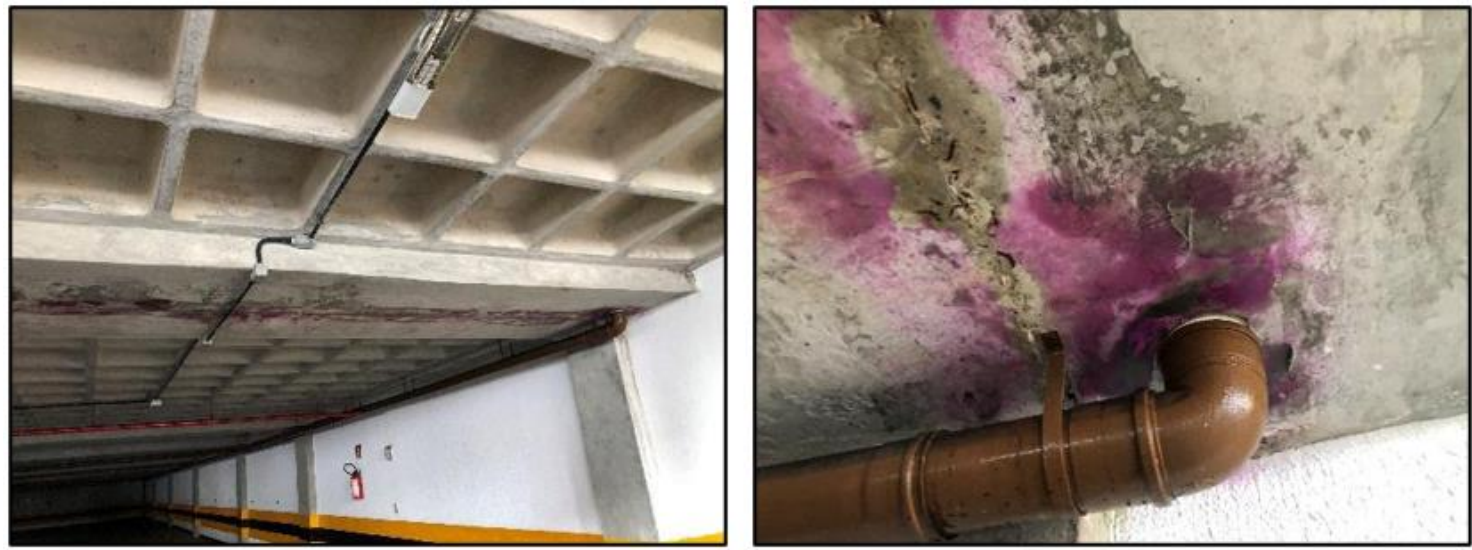

Figura 15 - Infiltração na calha abaixo da junta de movimentação do pavimento G2

De forma semelhante ao observado em outros pavimentos, foi identificada fissura ao longo do encontro entre viga e laje, além da degradação do selante na junta de movimentação do piso, com acúmulo de água nas proximidades (Figura 16 e Figura 17). Também se mostrou presente a infiltração na parede de entrada, confirmada por meio da termografia (Figura 18).
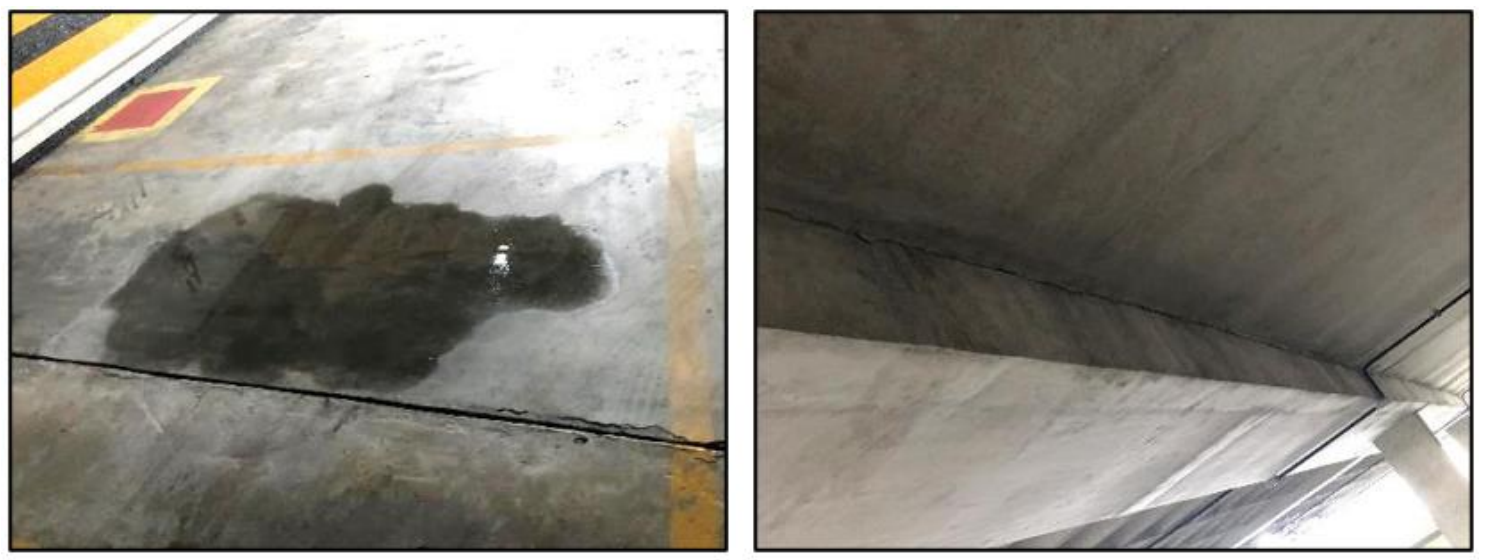

Figura 16 - Acúmulo de água próximo à junta (esq.); Fissura no encontro da viga com laje (dir.) 

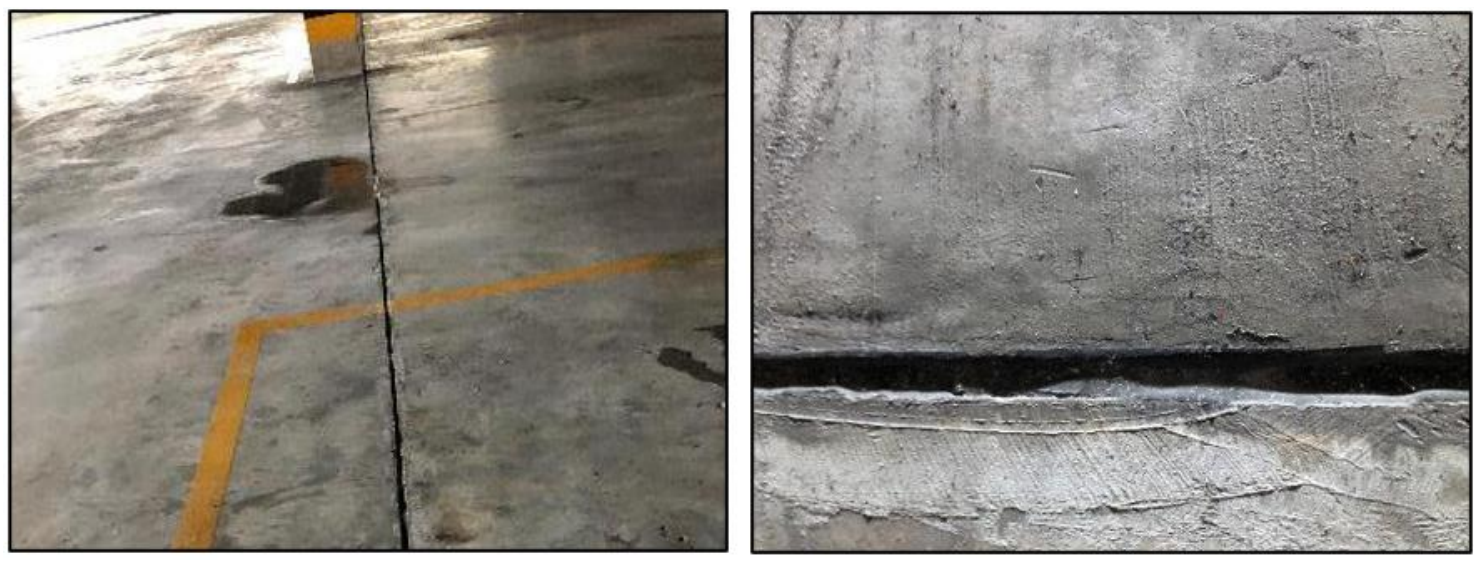

Figura 17 - Danos na junta de movimentação do piso

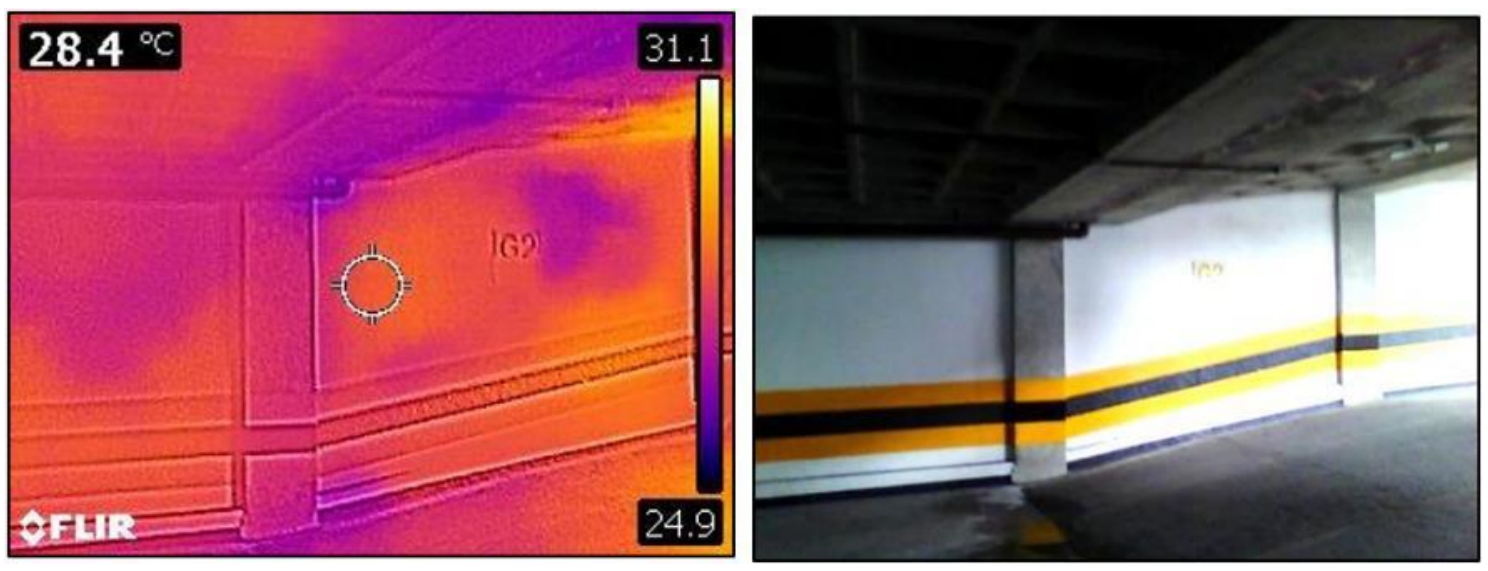

Figura 18 - Termograma da parede de acesso G1-G2

\subsection{Garagem do térreo}

Na garagem do térreo também se observou degradação do selante da junta de dilatação, acúmulo de água e fissuras no piso (Figura 19, Figura 20) e infiltração na parede lateral da rampa de acesso (Figura 22), sendo também encontrado um pedaço de madeira apodrecido, remanescente do processo construtivo (Figura 19 - dir.) e fissuração decorrente de corrosão no dente Gerber e viga adjacente (Figura 21).
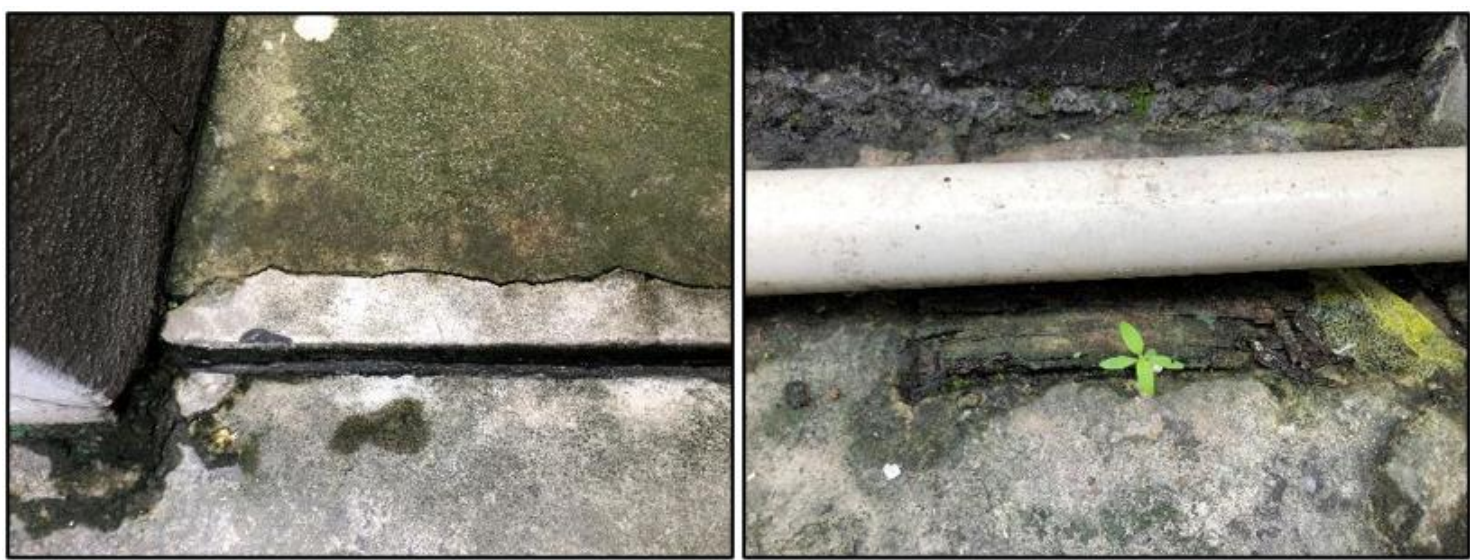

Figura 19 - Degradação do selante e região próxima à junta (esq.); Apodrecimento de madeira no piso (dir.) 

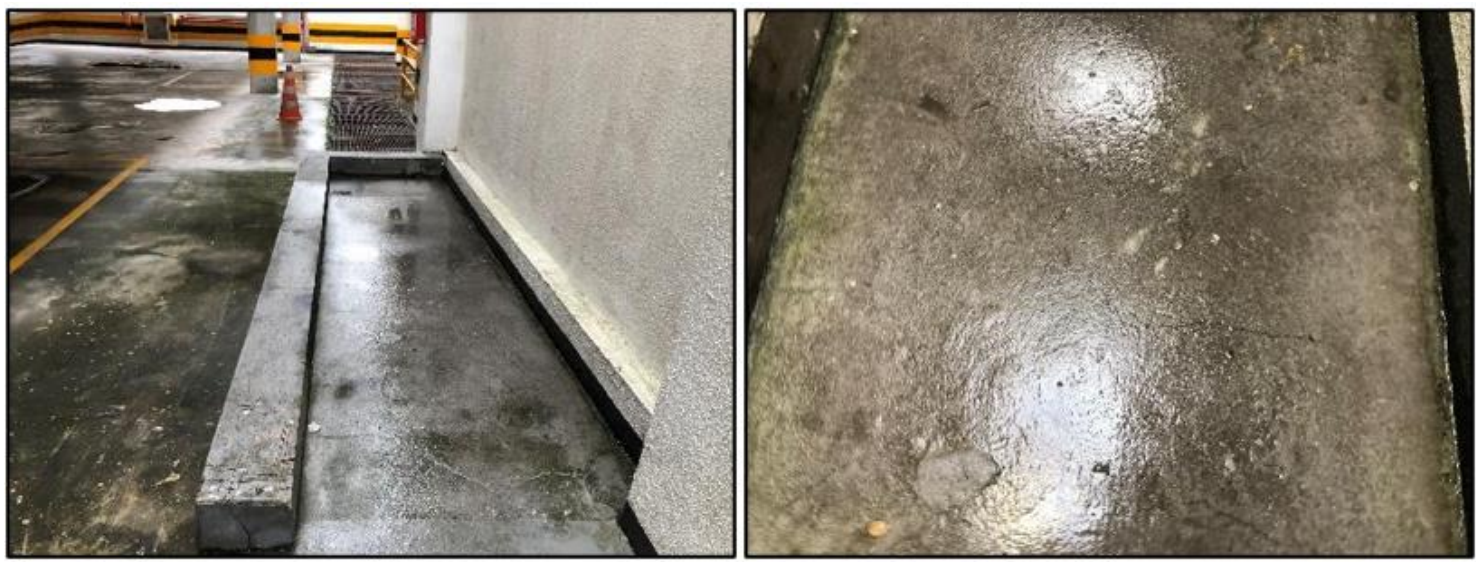

Figura 20 - Acúmulo de água (esq.); Fissuração no piso (dir.)
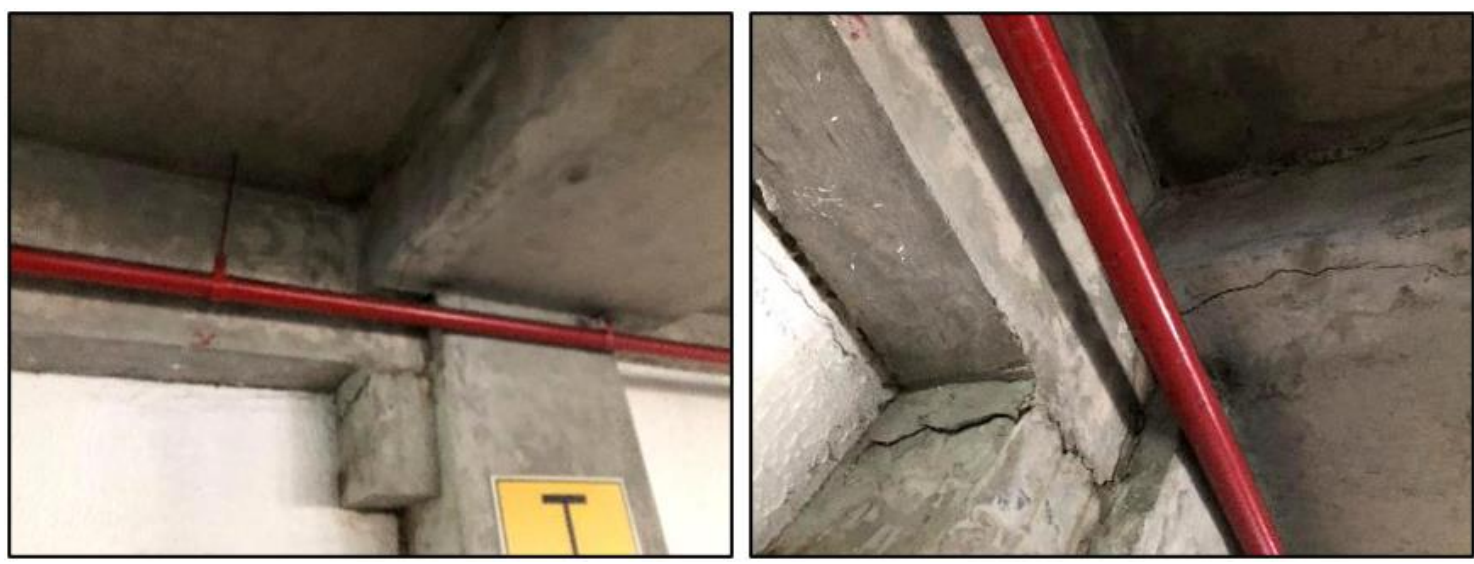

Figura 21 - Fissuras no dente Gerber e viga do térreo
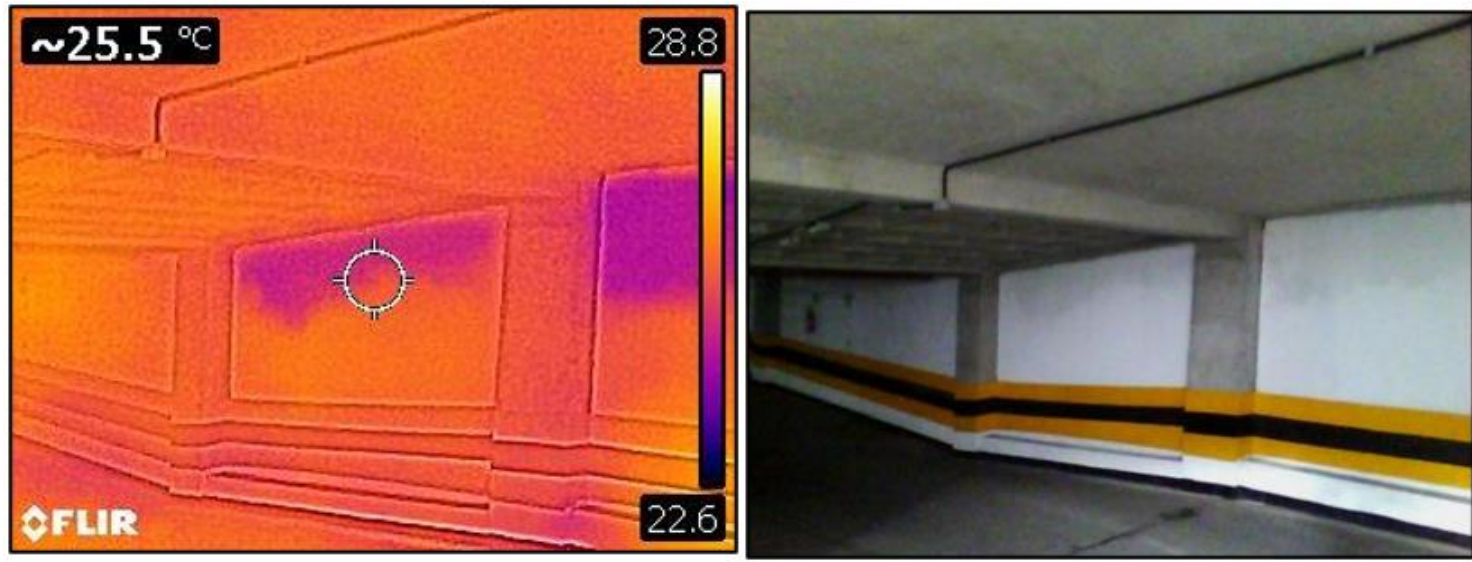

Figura 22 - Termograma da parede de acesso Térreo-G1

\subsection{Garagem do subsolo}

Na garagem do subsolo também foi identificada corrosão no dente Gerber e na viga adjacente (Figura 23), fissuração entre viga e laje (Figura 24) e grande infiltração ocorrendo na parede de fundo, que fica na região frontal da edificação, sendo identificados diversos manchamentos, acúmulo de água e sinais de antigos reparos na parede (Figura 25 e Figura 26). Na região afetada há um muro de arrimo como contenção, com relatos de maior incidência da infiltração de água em períodos de chuva. Verificando a frente da edificação, na região limítrofe da parede, foram identificados danos próximos à junta do piso que podem estar contribuindo para a infiltração de água no terreno (Figura 28 e Figura 29). Também foi encontrado vazamento em uma das tubulações do pavimento (Figura 27). 

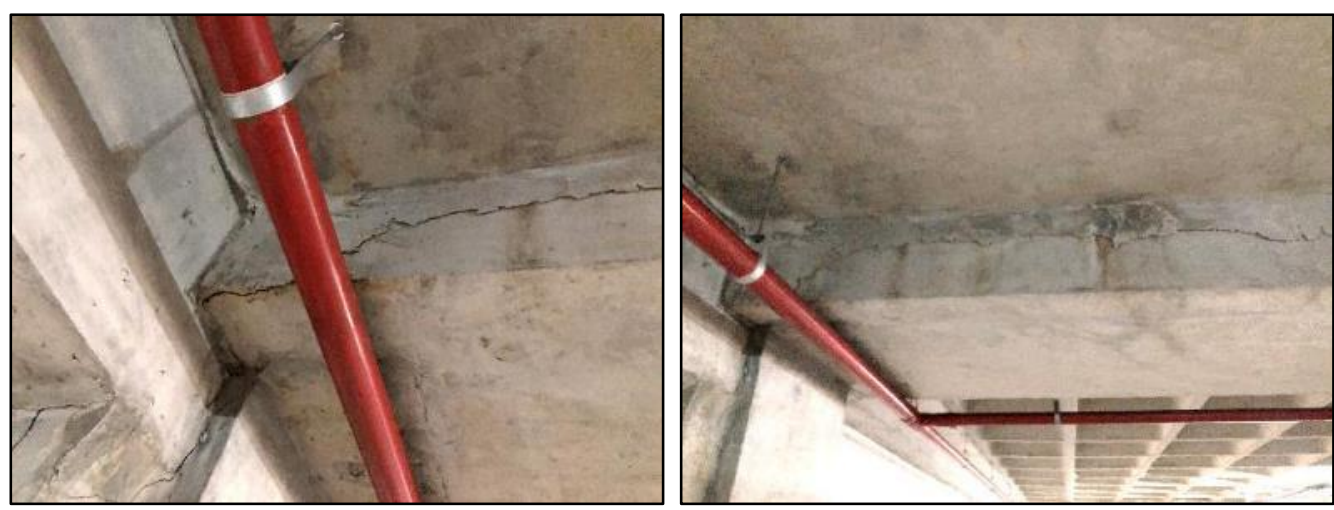

Figura 23 - Fissuras no dente Gerber e viga
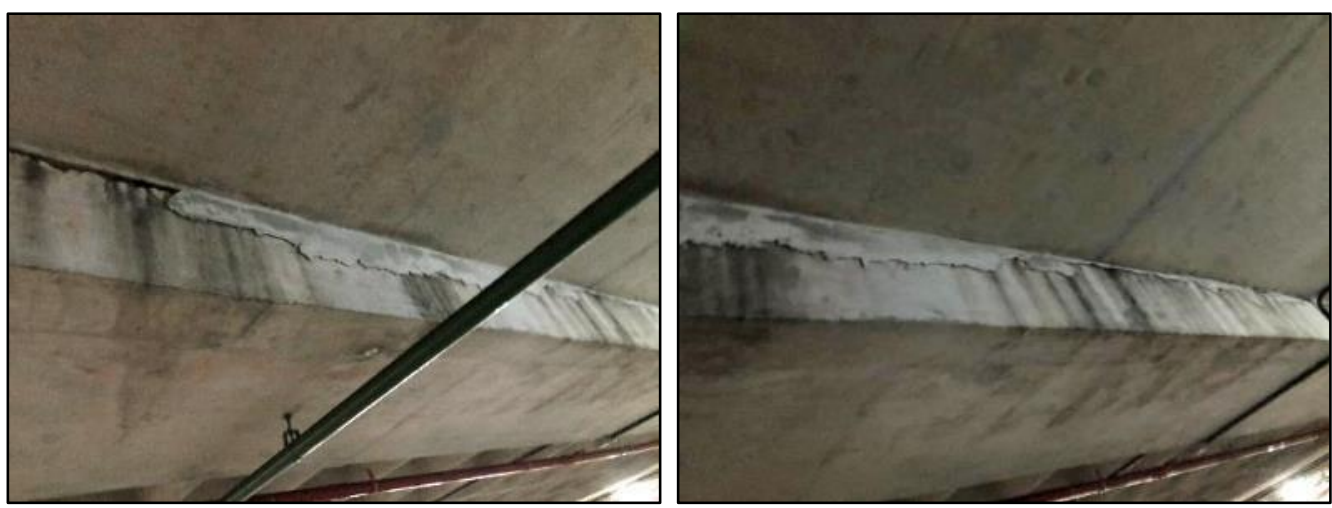

Figura 24 - Fissura na viga abaixo da junta de movimentação
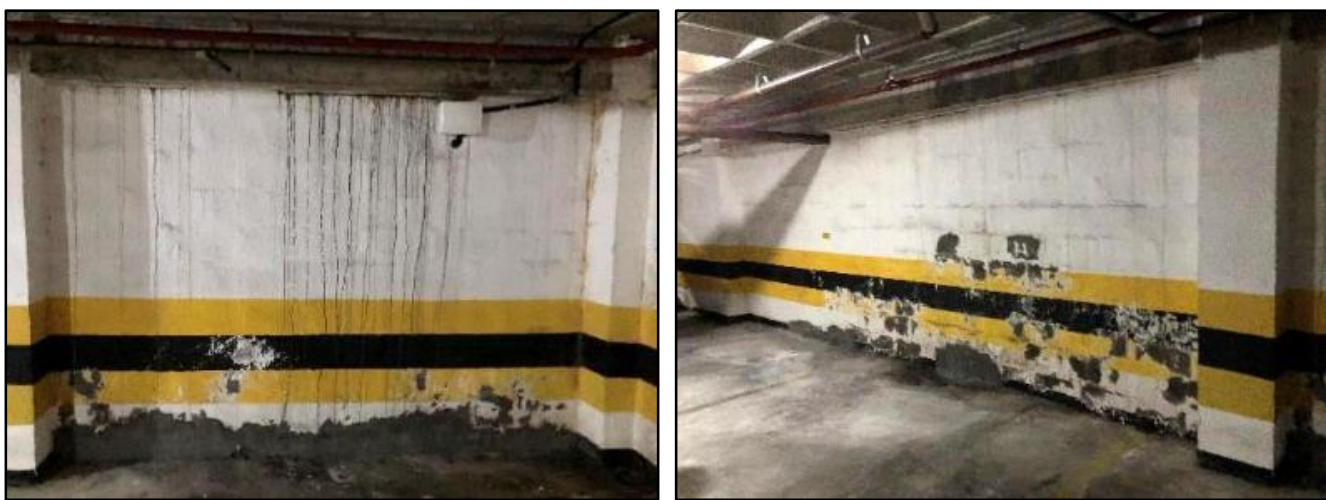

Figura 25 - Infiltração na parede da garagem
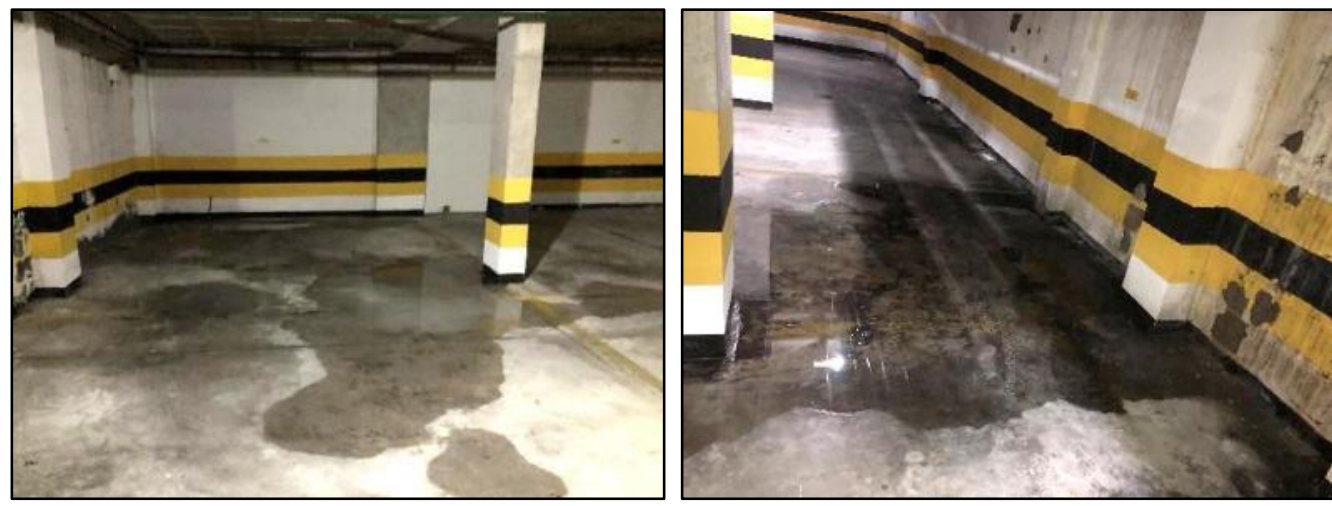

Figura 26 - Acúmulo de água devido à infiltração pelas paredes 

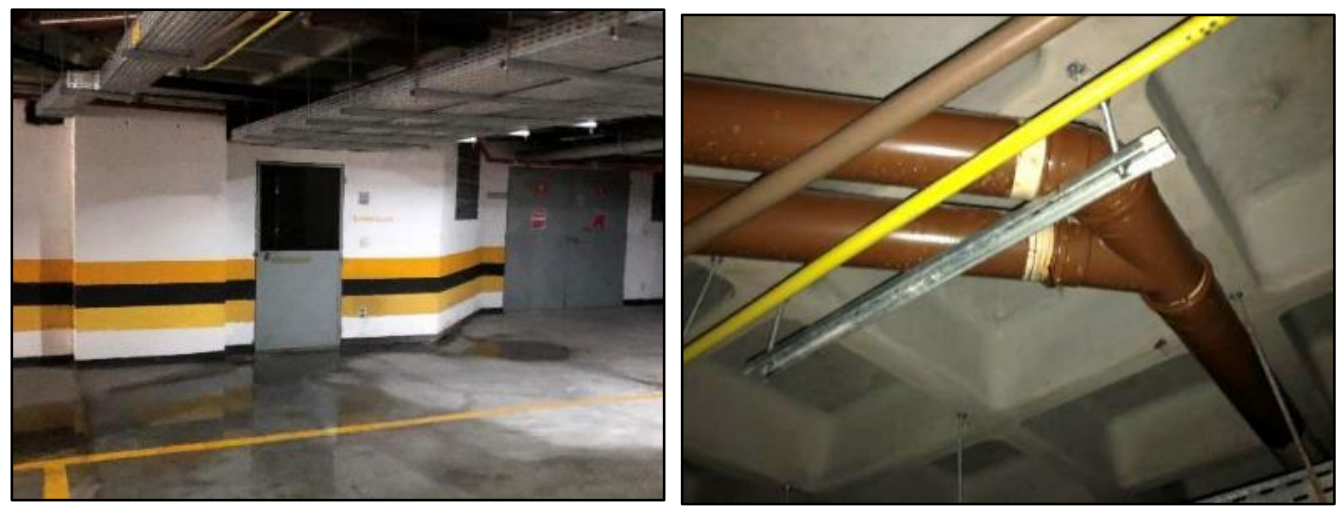

Figura 27 - Acúmulo de água e infiltração advindo da tubulação
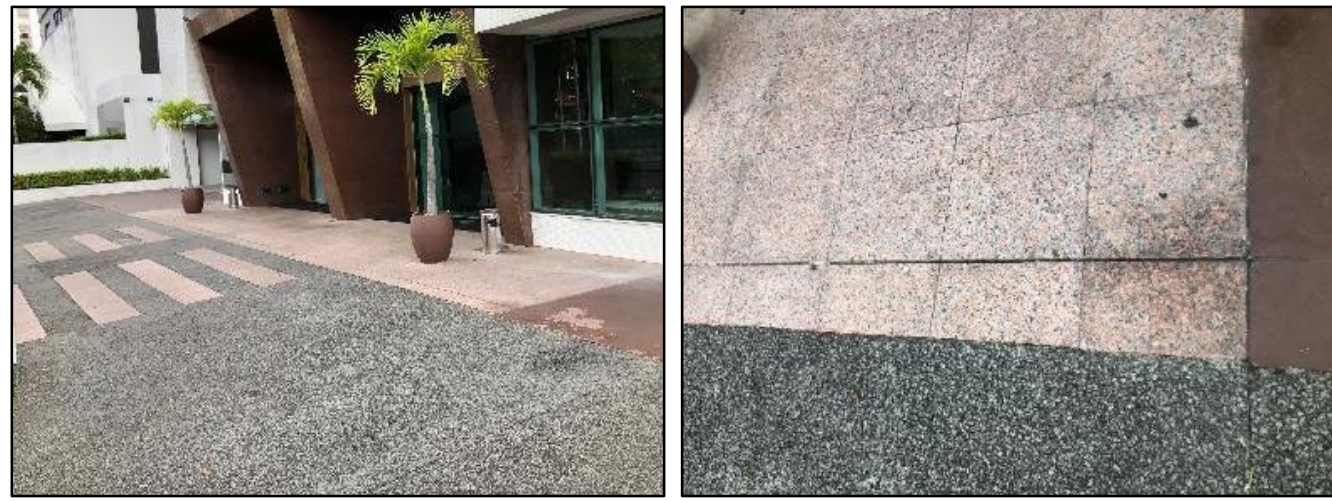

Figura 28 - Região frontal da edificação, limite do muro de arrimo do subsolo
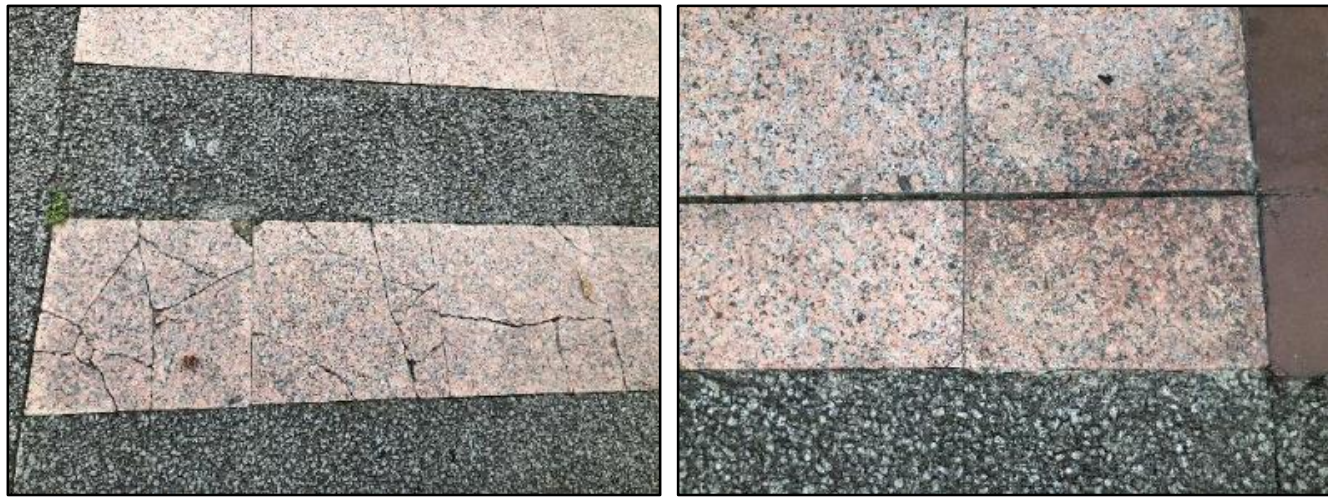

Figura 29 - Danos no piso na região frontal acima do muro de arrimo do subsolo

\subsection{Análises e soluções}

De maneira geral, foram identificadas manifestações patológicas de infiltração devido à degradação das juntas de dilatação do piso das garagens, nas paredes das rampas de acesso devido a fissuras na fachada, fissuras na sarjeta do pavimento G2 e descolamento da manta de impermeabilização da cobertura e pisos G2 e G3. A solução recomendada para estes casos é a recuperação das juntas de dilatação do piso, principal caminho de passagem da umidade. De forma semelhante, deve-se recuperar as fissuras encontradas nas sarjetas das rampas de acesso e proceder com o restauro do sistema de impermeabilização na região dos rodapés das muretas, atentando-se para a correta fixação da manta asfáltica na alvenaria com a devida remoção da camada de polietileno para garantia da aderência do sistema. A metodologia de fixação da manta na superfície vertical deve ser avaliada em projeto de impermeabilização, podendo ser realizada com uso de tela metálica, cinta perfurada, chanfro na alvenaria, entre outras.

Os pontos onde foram encontrados elementos remanescentes do processo construtivo são os reparos mais simples, devendo-se proceder com sua remoção e reconstituição do revestimento na área afetada. 
Na garagem do subsolo há intensa infiltração na região do muro de arrimo, sendo identificados pontos potencialmente infiltrantes na entrada da edificação com fissuras, falhas de rejunte e jardins. Com base em informações das edificações vizinhas, há presença de lençol freático muito raso na região, o que potencializa a ocorrência encontrada. Para este caso, é recomendada a eliminação dos pontos potencialmente infiltrantes, construção de sistemas de drenagem e, em caso de reincidência, a construção de um reservatório de nível. Como sistema drenante, sugere-se a execução de tubos drenantes no muro de arrimo (Figura 30), com devido escoamento da tubulação para o sistema de drenagem. Neste caso, um engenheiro geotécnico deve ser consultado para avaliar a execução do sistema sem comprometimento da estabilidade do maciço.

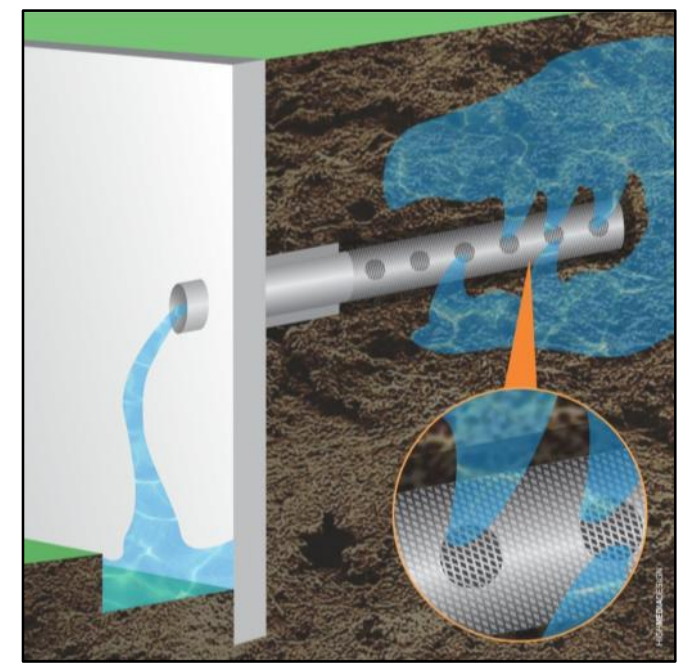

Figura 30 - Exemplo esquemático de tubo drenante

A corrosão nos elementos estruturais é preocupante e, apesar de não ser diagnosticado um risco estrutural elevado, recomenda-se que seja realizada intervenção imediata, principalmente nos apoios (dentes Gerber), obedecendo-se as recomendações de segurança estrutural com o devido escoramento da estrutura durante intervenção com participação indispensável de engenheiro estruturalista. Durante a recuperação, deve-se escarificar o concreto expondo a armadura até uma profundidade de 10 a $15 \mathrm{~mm}$ por trás das barras de aço, o suficiente para possibilitar a remoção da oxidação nas barras por lixamento e aplicação de primer anticorrosivo. É de extrema importância que seja verificada a perda de seção da armadura, sendo consultado engenheiro estruturalista para determinação da necessidade de reforços.

\section{Conclusões}

Dado o exposto, fica evidente a importância da manutenção adequada dos sistemas de impermeabilização, drenagem e juntas de movimentação, visto que a maioria das manifestações patológicas encontradas teve sua causa associada à penetração de água devido à degradação de algum destes sistemas, promovendo a ocorrência de outros fenômenos deletérios como fissuração por movimentação higrotérmica e corrosão.

Também se confirmou o potencial da termografia infravermelha como técnica para detecção de infiltrações e presenças associados à umidade, permitindo que as regiões fragilizadas sejam identificadas e tratadas ainda nos momentos iniciais da patologia, evitando que o avanço da degradação prejudique outros sistemas ou acarrete maiores custos de manutenção em momentos tardios. Tal característica ficou evidente durante o estudo, sendo identificadas regiões com infiltração originária de danos na fachada mesmo nas paredes internas onde existiam poucos ou nenhum sinal indicativo.

\section{Agradecimentos}

Agradecemos à Fundação de Amparo à Pesquisa do Estado da Bahia (FAPESB) pelo apoio financeiro e incentivo à pesquisa. 


\section{Referências Bibliográficas}

ABNT - Associação Brasileira de Normas Técnicas. (2013). NBR 15575-1: Edificações habitacionais Desempenho Parte 1: Requisitos gerais, Rio de Janeiro.

ABNT - Associação Brasileira de Normas Técnicas. (2014). NBR 6118: Projeto de estruturas de concreto Procedimento, Rio de Janeiro.

Antunes, G. R. (2010) Estudo de manifestações patológicas em revestimento de fachada em Brasília sistematização da incidência de casos. Dissertação de Mestrado. Universidade de Brasília, Brasília.

Barreira, E.; Almeida, R. M. S. F.; Delgado, J. M. P. Q. (2016). Infrared thermography for assessing moisture related phenomena in building components. Construction and building materials, v. 110, p. 251-269.

Dal Molin, D. C. C., Masuero, A. B., Andrade, J. J. O, Possan, E., Masuero, J. R., Mennucci, M. M. (2016). Contribuição à Previsão da Vida Útil de Estruturas de Concreto. Avaliação de Desempenho de Tecnologias Construtivas Inovadoras: Materiais e Sustentabilidade. p. 223-270. Editora Scienza.

Lisboa, D. W. B., Da Silva, A. B. S., De Souza, A. B. A., Da Silva, M. P. (2018). Utilização de VANT na inspeção de manifestações patológicas em fachadas de edificações. Congresso Técnico Científico da Engenharia e da Agronomia, Maceió.

Magalhães, R. A. B., Assunção, R. F. A., Silva, L. S. S., Ferreira, M. S., Assunção, W. R. (2019). Estudo de caso de patologias causadas pela umidade face a inexistência de implantação do sistema de impermeabilização nas garagens do 1 으 e 2 o subsolo de um edifício residencial multifamiliar de múltiplos pavimentos em Belém/PA. RCT-Revista de Ciência e Tecnologia, v. 5, n. 9.

Oliveira, M. V. T. Avaliação das causas e consequências das patologias dos sistemas impermeabilizantes: um estudo de caso. 2015. 78 f. Trabalho de conclusão de curso (Bacharelado - Engenharia Civil) - Universidade Estadual Paulista, Faculdade de Engenharia de Guaratinguetá, 2015.

Ribeiro, F. A.; Barros, M. M. S. B. (2010). Juntas de Movimentação em Revestimentos Cerâmicos de Fachada. São Paulo: Pini.

Rocha, J.H.A., Santos, C.F., Oliveira, J.B., Albuquerque, L.K.S., Póvoas, Y.V. (2018). Detecção de infiltração em áreas internas de edificações com termografia infravermelha: estudo de caso. Ambiente construído, Porto Alegre, v. 18, n. 4, p. 329-340.

Santos, C. F.; Rocha, J. H. A.; Povoas, Y. V. (2019). Utilização da termografia infravermelha para detecção de focos de umidade em paredes internas de edificações. Ambiente construído. Porto Alegre, v. 19, n. 1, p. 105-127, Mar.

Schuler, A. (1998). Caracterização de argamassas com adições de sílica ativa como material para reparos e reforços de estruturas de concreto armado. Dissertação (Mestrado). Curso de Pós-graduação em Engenharia Civil, Universidade Federal do Rio Grande do Sul, Porto Alegre.

Tondelo, P. G., Barth, F. (2019). Análise das manifestações patológicas em fachadas por meio de inspeção com VANT. PARC - Pesquisa em Arquitetura e Construção, v. 10. 